\title{
DOES FINANCIAL DEVELOPMENT ABSORB OR AMPLIFY THE SHOCK?
}

\author{
Meily Ika Permata \\ Ibrahim \\ Hidayah Dhini Ari ${ }^{1}$
}

\begin{abstract}
This paper analyzes the role of financial development on economic output in Indonesia. Using vector autoregressive method, the results confirm the positive impact of financial development on output growth. The interaction between the financial development and the shock either in financial or real sector shows that the financial development has a positive role to dampen the negative impact of the shock on the output growth, while strengthen the positive one. Another variable on the model, which significantly affect the output growth are excess money, term of trade, and the price. Compare to these variables, the marginal effect of financial development on output is smaller.
\end{abstract}

Keywords : Financial development, shock, output volatility, VAR.

JEL Classification : E44, 016

1 Meily lka Pertama (meily@bi.go.id), Ibrahim (ibrahim@bi.go.id) and Hidayah Dhini Ari (dhini_ari@bi.go.id) are researchers in Economic Research Bureau, Directorate of Economic and Monetary Policy Research. The author thanks to Dr. Noer Azzam, Dr. Perry Warjiyo, Dr. Iskandar Simorangkir and other colleagues in DKM for the excellent input and suggestion. 


\section{INTRODUCTION}

Macroeconomics stability is a necessary condition for sustainable economic development. Therefore, efforts to understand the sources of macroeconomic instability condition is one of the challanges of the important attention in economics.

Role of the financial sector is associated with economic growth that has long been a subject research, especially after Schumpeter $(1912)^{2}$. Since then, continues studies have been conducted to examine the interaction between financial development and output growth. Based on review of various conducted studies, the relationship between financial development and output growth tend to be inconclusive.

Some views believe that the financial development will drive the growth (initiated by Schumpeter, 1911 and Gurley and Shaw, 1995) because financial sector can overcome the problem of financial constraint, contribute to the allocation of resources more efficiently, channel funding and other activities related to risk sharing and financial innovation, be the medium for the monetary policy transmission (Cecchetti and Krause, 2001 and Krause and Rioja, 2006), and can overcome the problem of imperfect capital market) (Bernanke and Gertler (1989), Greenwald and Stiglitz (2003) and Kiyotaki and Moore (1997). Financial development is also believed to have positive role in reducing the volatility of macroeconomic variables,(Dynan, Elmendorf and Sichel (2006), Denizer, Iyigun, and Owen (2002), Harvey and Lundblad (2006), Aghion et. al (2005), Aghion et. al (2009), Cecchetti, Lagunes and Krause (2006), and Mendicino (2007)).

However, Bacchetta and Caminal (2000), Easterly et al. (2002) and Kuneida (2008), show that the financial constraint can be a factor that restrain or even exacerbate the shock impact that occured in the economy. Meanwhile, Lopez and Spiegel (2002), denizer et al. (2002), Silva (2002), and Tharavanji (2007) actually found negative relationship between financial development and output volatility. Other researchers such as Tiryaki (2003), Beck (2006) \& Guryal et al. (2007) did not find significant relationship between financial development and growth volatility.

The output volatility shown on the figure, suggest a need to conduct empirical testing about the role of financial sector in macroeconomic stability, especially GDP growth in Indonesia. As one of the developing countries with a growing financial sector, the study about the role of financial sector in the context of macroeconomic stability is expected to assist the formulation of a more appropriate monetary policy. When compared to some developed countries, the output volatility in emerging countries is generally higher, except the period of global crisis. Among emerging countries, Indonesia's output volatility post-crisis in 1997 looks relatively smaller.

2 Schumpeter, J.A., 1991. The Theory of Economic Development. Cambridge, Mass: Harvard University Press 

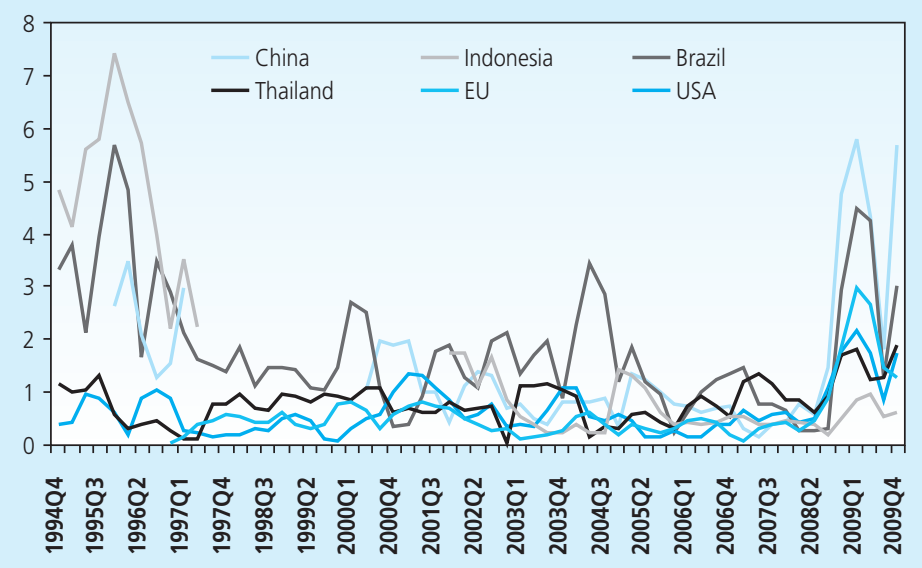

Figure 1. Output Volatility in Developing and Emerging Countries

Explicitly, this paper identifies the relationship between the role of financial sector and output volatility in Indonesia. To measure the financial development we use the ratio of credit to private sector towards GDP. This measure commonly used in previous studies. The conclusive relationship between financial developmentsto macroeconomic stability is expected to be a valuable input in formulating better monetary policy.

The second part of this paper reviews the theory and literature, the third part review the methodology and empirical models are used, while the results and analysis are described in the fourth. Conclusions, implication and policy recommendation will close the presentation.

\section{THEORY}

The view that financial development will drive the growth (started by Schumpeter, 1911 and Gurley and Shaw, 1955) is based on the view that the financial sector can overcome financial constraint. In addition, the existence of financial sector contributes to the allocation of resources, both financial and non-financialmore efficiently. Financial deepening and development of can reduce volatility in economy, through its ability to channel financing and other activities related to risk sharing and financial innovation.

Financial sector contributes in stabilizing macroeconomic condition in general through its ability to be the medium for the monetary policy transmission (Cecchetti and Krause, 2001 and Krause and Rioja, 2006). Bernanke and Gertler (1989), Greenwald and Stiglitz (1993) and 
Kiyotaki and Moore (1997) carry out a study and confirm the view above, by showing that financial sector contribute to overcome the problem of imperfect capital market, and there by reduce output volatility in economy.

Dynan, Elmendorf and Sichel (2006) and Denizer, lyigun, and Owen (2002) and Beakaert, Harvey and Lundblad (2006) present the results of study showing that financial development have a positive role in reducing the volatility of macroeconomic variables. Aghion et al. (2005) and Aghion et al. (2009) confirm that credit constraint contribute to enlarge the shock impact in economy through the choice of type investment made by businesses. Cecchetti, Lagunes and Krause (2006) and Mendicino (2007) prove that the consumption credit have a positive role in overcoming liquidity constraint at the household level so that it can reduce the volatility of economic growth.

However, Bacchetta and Caminal (2000) show that financial constraint can be a factor that restrain or even exacerbate the shock impact that occured in the economy, depending on the type of shock that occured in the economy. In line with Bacchetta and Caminal, Easterly et al. (2002) and Kuneida (2008) indicate the characteristic of relationship between financial development and economic growth tends to be nonlinear. In this case, financial development will reduce macroeconomic volatility to a certain point, beyond that point, more credit to private sector will increase the volatility.

Meanwhile, Lopez and Spiegel (2002), Denizer et al. (2002), Silva (2002), and Tharavanji (2007) actually found a negative relationship between financial development and the volatility of economic growth. More interestingly, Tiryaki (2003), Beck (2006) and Guryay et al. (2007) did not find significant relationship between financial development and volatility growth.

Based on several conclusions from various research above, the relationship between financial development and output volatility is still ambiguous or inconclusive. That characteristic of relationship depends on the source of the shock on economy, whether it comes from the real or monetary sector, and how an economy responds to the shocks.

One simple model about financial development was built by Bacchetta and Caminal (2000), and then developed and modified by Beck (2006). The model assumethe economy consists of consumers and entrepreneurs. Every entrepreneur has the same access to production technology, represented by $f(k)$, with $f(0)=0, f^{\prime}(k)>0$, and $f^{\prime \prime}(k)<0$. Although each entrepreneur has same access to production technology, entrepreneur basically has a different level of wealth $b$. As much as $\beta$ ratio of the entrepreneur is entrepreneur with high wealth. And as much as $(1-\beta)$ ratio of the entrepreneurs are those with low wealth. High group is assumed to be able to meet the financing needs of its investment and has excess funds in the bank and 
get the interest rate $r^{D}$. In addition, High is assumed to have no financing constraint in financial market, and thereby High profit maximization is achieved at :

$$
f^{\prime}\left(k^{H}\right)=r^{D}
$$

Meanwhile, Low has limited financing so that had to borrow funds with interest rate $r^{L}$. The existence of assymetric information and moral hazard potentially cause the Low group to bear an agency cost $\varphi$. With this condition, Low profit maximization is achieved at:

$$
f^{\prime}\left(k^{L}\right)=\varphi r^{L}, \varphi \geq 1
$$

Thus, the relative marginal productivity between High and Low is :

$$
\frac{f^{\prime}\left(k^{L}\right)}{f^{\prime}\left(k^{H}\right)}=\varphi \frac{r^{L}}{r^{D}}
$$

The greater the difference between $r^{L}$ and $r^{D}$ and $\varphi$, the higher ratio $k^{H} / k^{L}$ and the greater the difference of marginal productivity between Low and High. The higher $\varphi$, the greater effect of real location funds between High and Low. This real location funds will influence aggregate productivity and ultimately economy's output as a whole.

The financial intermediaries, in this case is bank, is assumed to work in a perfect competition condition, without cost, and only holds the asset in the form of credit. However, the bank deposit is subject to reserve requirement of the monetary authority, that is $\tau$. Thus, the credit can be allocated by bank to Low $(1-\tau)$ is multiplied by the deposits of High. Thus, the increase of $\tau$ will reduce funds available for loan forthe Low, and vice versa. Total aggregate of loans from bank is:

$$
(1-\tau) \beta\left(b^{H}-k^{H}\right)=\left(k^{L}-b^{L}\right)(1-\beta)
$$

where $b^{H}$ is internal funds of High and $k^{H}$ is the desired level of investment of group High. While $k^{L}$ and $b^{L}$, respectively, is the level of investment desired by Low and their internal funds. Low internal funds areassumed to be very small so that it cannot meet the level of their desired investment.

Furthermore, assuming there is no possibility of default, then the ratio of $r^{L}$ and $r^{D}$ is only influenced by the size of reserve requirement, $\tau$, hence: 


$$
\frac{r^{D}}{r^{L}}=(1-\tau)
$$

With the existence of assymetric information that generates agency cost, then Low naturally will always face sub-optimal investment condition. This means the realized level of investment will always below the desired level. In this case, agency cost stated as:

$$
\varphi=\omega\left(1-\frac{b^{L}}{k^{L}}\right)
$$

Where $\omega$ is a function of several technological parameters, which are exogenous. This means that agency cost is a negative linear function of ratio between Low's internal funds owned and their desired level of investment. The greater internal funds owned, the smaller the agency cost charged by bank to Low. Furthermore, in this case, is:

$$
f^{\prime}\left(k^{L}\right)=r^{L} \omega\left(1-\frac{b^{L}}{k^{L}}\right)
$$

Equation (6) shows that Low will be exposed to credit-constrained condition, so that the level of investment that might be achieved will lower than the desired one. Low's level of investment will decrease with the increaseof $r^{L}, \omega$, and the leverage ratio $\frac{k^{L}}{b^{L}}$.

Based on the equations above, then the marginal productivity of High and Low can be elaborated in following equation:

$$
\frac{f^{\prime}\left(k^{L}\right)}{f^{\prime}\left(k^{H}\right)}=\omega\left(1-\frac{b^{L}}{k^{L}}\right) \frac{r^{L}}{r^{D}}=\omega\left(1-\frac{b^{L}}{k^{L}}\right)\left(\frac{1}{1-\tau}\right)
$$

Thus, the market clearing condition in financial market is:

$$
\beta b_{t}^{H}+(1-\beta) b_{t}^{L}=\beta k_{t}^{H}+(1-\beta) k_{t}^{L}+\tau \beta\left(b_{t}^{H}-k_{t}^{H}\right)
$$

Based on equation (7) and (8), we can seethat the relative investment $k^{L} / k^{H}$ will increase along with the increase of ratio $b^{L} / k^{L}$ and the relative ratio of internal funds $b^{L} / b^{H}$ and declining agency cost $\omega$, and reserve requirement $\tau$. 
Based on the equations above, we can obtain some interpretation below:

1) The impact of shocks that occur in the real sector will be largerin the presence of assymetric information condition on capital market. The impact was even greater in line with the increase in agency cost $\omega$. This is shown in equation (7), where the investments of the High will be greater than the Low, so that causing the Low marginal productivity is higher than in High. The difference of marginal productivity will be greater with higher agency cost; a condition found in the capital market conditions that characterized assymetric information. With in creasing magnitude of the difference of marginal productivity, then the impact of shocks to the economy's output will be greater.

2) The impact of shocks coming from monetary policy affects the supply of loan able funds will have smaller impact on the conditions where there is assymetric information on the capital market. Relaxing the monetary policy in the form of reduction of level reserve requirement, would increase the amount of loan able loan that will eventually degrade. Never the less, the reduction in interest rates will increase the leverage and eventually agency cost for the Low. This in turn will reduce some of the positive impact of reserve requirement reduction. Mean while, the decline in agency cost as a result of the growing of financial development will further streng then the positive impact of reduction in reserve requirements to the output.

These should be the the base of our hypothes is to be tested on this paper.

\section{METHODOLOGY}

This study will use an econometric approach to test the testable hypothesis by utilizing the method of vector autoregression (VAR). We use this VAR method to test the case of Indonesia.

VAR model is a linear function analysis of past data movement of a set of variables (endogenous variable) in the same period $(t=1, \ldots, T)$. A VAR model of order $(p)$ can be represented in the following equation:

$$
x_{t}=A_{0}+A_{1} x_{t-1}+A_{2} x_{t-2}+\ldots+A_{p} x_{t-p}+e_{t}
$$

Which $e_{t}$ is a vector from error term that meet the standard condition; $\mathrm{E}\left(e_{t}\right)=0$, and $\mathrm{E}\left(e_{t} e_{t}\right)$ $=\Omega$.

VAR model is often used in macroeconomic analysis. However, although the VAR approach has the advantage in modeling dynamic behavior of economic variable and 
forecasting, many criticism directed against VAR approach which tends to be a-theory, where the lack of restriction in the VAR model lag structure is associated with the lack of a structure underlying the relationship among variables in the VAR system. This would create difficulties in interpreting the results.

The theoretical model described previously has provided a hypothesisto be tested. But the test to perform is not solely based on a reduced form derived explicitly from the model above, but rather we use empirical ad hoc model in order to accommodate some other control variables that are not captured explicitly in theoretical model.

Some of the variables to be included in the model are real GDP growth and price movements, in order to illustrate the volatility of macroeconomic variables. Also included are variables in real and monetary sectors. For the real sector, we can use terms of trade variable for instance, while for monetary sector we may use excess money. Financial development $(F D)$ is measured with the credit ratio to GDP. Meanwhile, to capture a market imperfection/assymetric information, we can usea variable that can explain the existence of risks such as interest spread between lending and SBI rate.

The data used in this study are quarterly data, covering first quarter period of 1997 to second quarter of 2010. The variables involved are, (i) Real GDP, representing the output, (ii) Consumer Price Index, (iii) Term of trade, representing the shock from real sector, (iv) Excess money, represents shock from monetary sector, (v) Ratio of credit to GDP, measuring the financial development, (vi) Interest rate spread between lending rate and the SBI rate, measuring the magnitude of risk due to the existence of market imperfection/assymetric information.

\section{RESULTS AND ANALYSIS}

In general, the macroeconomic indicator in Indonesia at the beginning of the observation period had a relatively high volatility movement. During the period ofcrisis in 1998, the economic growth contracted by more than $13.1 \%$ and inflation jumped to $69.8 \%$ followed by a variety of other indicators such as the ratio of credit to GDP, the excess money, and the risk indicators represented by the spread of lending rates to SBI (Figure 5). These volatilities were getting smaller along with the improvement of monetary management.

By looking at the more detail movement on standard deviation of the macroeconomic and the financial indicators, we can obtain a clearer picture. In general, the volatility of GDP with other variables has same direction. The correlation of growth volatility with the 


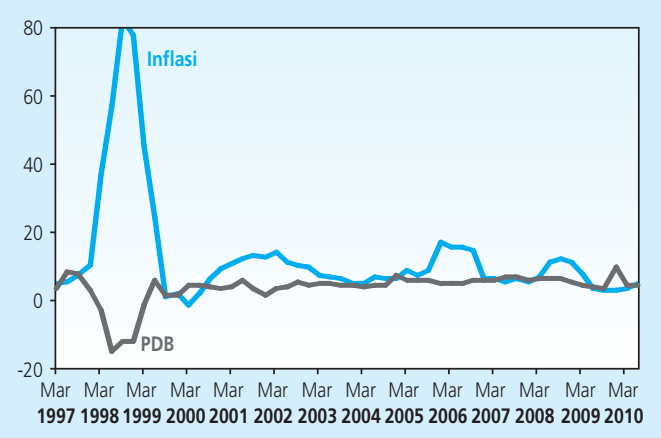

Figure 2.

The Main Indicators Development

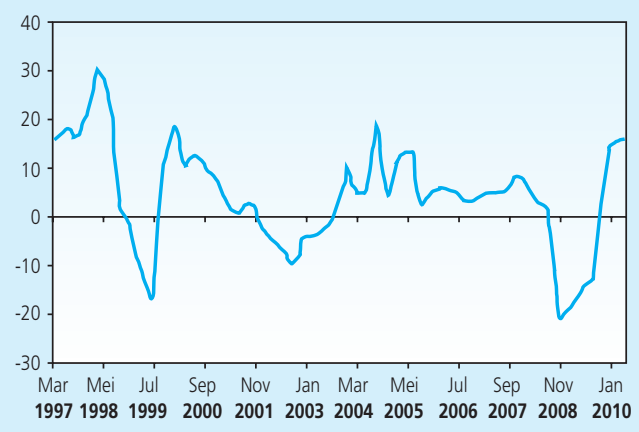

Figure 4.

Excess Money

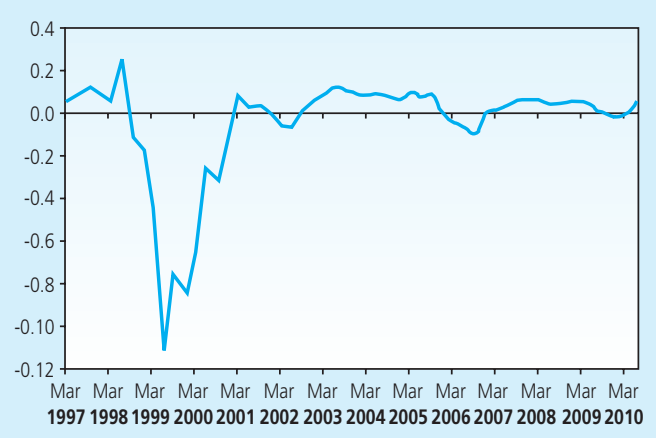

Figure 3.

The Financial Development (dln FD)

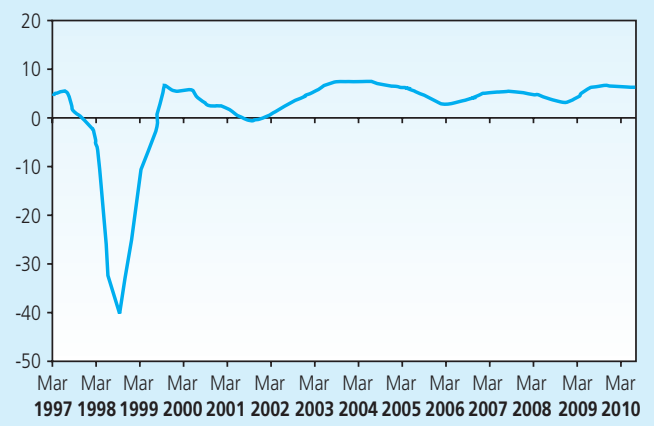

Figure 5.

Spread Credit Interest Rate-SBI

average of credit to GDP ratio reached $81 \%$ and the correlation between growth and inflation volatility by $78 \%$ (Figure 6 ). Volatilityin the figure is calculated by using the three years moving standard deviation for each indicator, then we calculate the pair correlations. Based on the initial hypothesis on the co-movement among these variables, we proceed to use the VAR method.

Prior the VAR estimates we run the stationary tests on each variable by using the Augmented Dickey Fuller (ADF) unit root tests. The test results show that GDP and IHK variables are non-stationary in levels (Table 1). Based on these unit root tests, the variables selected for inclusion in the VAR model is dLnPDB, dLnIHK, dLnTOT, dLnFD, risk growth and excess money growth. 

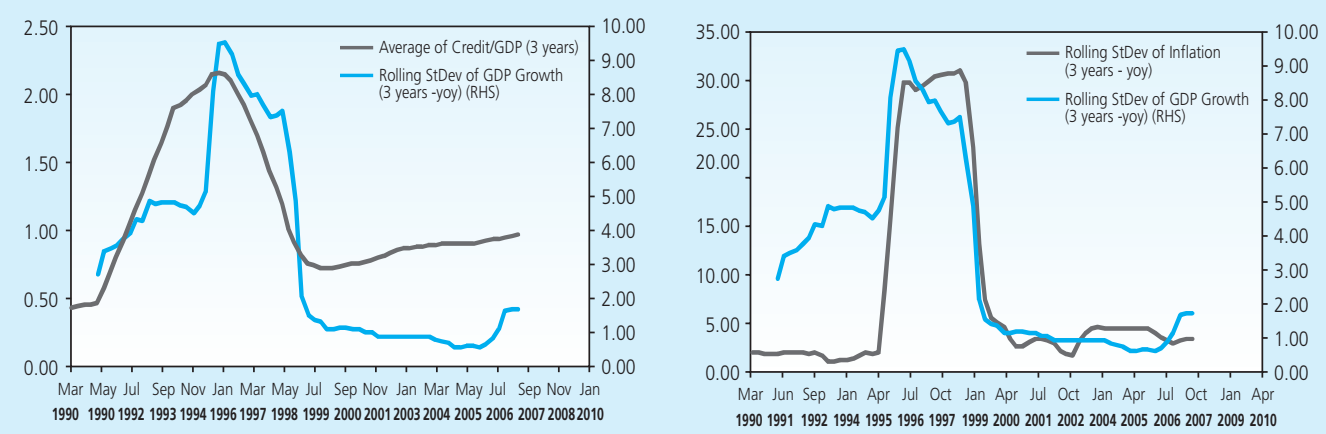

Figure 6.

The Connection Development of Main Indicator

\begin{tabular}{l|c}
\multicolumn{2}{c}{ Table 1. } \\
\multicolumn{1}{c}{ The Test Result of Unit Root Test } \\
GDP & Level (P-value) \\
dLnPDB & 1.0000 \\
GDP Growth & 0.0967 \\
CPI & 0.0943 \\
dLnIHK & 0.8050 \\
Inflation & 0.0006 \\
TOT & 0.3043 \\
dLnTOT & 0.0258 \\
TOT Growth & 0.0020 \\
FD & 0.0057 \\
dLnFD & 0.0163 \\
FD Growth & 0.0024 \\
Risk & 0.2049 \\
Growth Risk & 0.0000 \\
Excess Money Growth & 0.0000 \\
& 0.0002
\end{tabular}

Optimum lag order for VAR procedure showed mixed results. Based on the Schwartz Information Criteria, the optimal lag is 1, while the Akaike Information Criteria and Hannan Quinn Information Criteria generate optimal lag is 6 . However, the lag order 6 is not selected, since the number of observation is only 54. This study also did not follow the Schwart optimum lag with lag order 1 , but sets the use of lag order 2 to better capture the variables dynamics. Based on lag structure test, it is known that the estimated VAR with lag order 2 is stable with all roots smaller than 1 and is in the unit circle (Figure 7). 


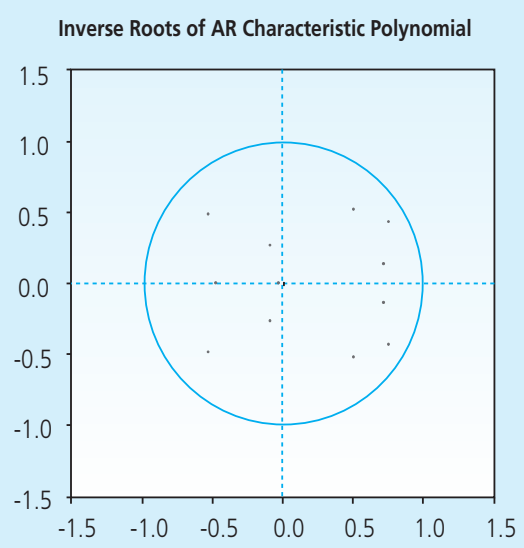

Figure 7.

AR Roots Graph

The results of Granger Causality/block exogeneity test showed that the simultaneous movement of inflation, TOT, excess money, financial development and the risk are the explanatory variable of the GDP movement (Table 2). However, individually the risk can not explain the GDP movement, but we keep it on the model since the risk is the control variables that describe the magnitude of risk due to the existence of market imperfection/assymetric information.

\begin{tabular}{l|r|r|c|}
\multicolumn{4}{c|}{ Table 2.} \\
VAR Granger Causality/Block Exogeneity Wald Tests \\
\hline \multicolumn{1}{|c|}{ Excluded } & Chi-sq & \multicolumn{1}{|c|}{ df } & Probability \\
DLNIHK & 17.48 & 2 & 0.000 \\
DLNTOT & 11.80 & 2 & 0.003 \\
EXCMON & 8.52 & 2 & 0.014 \\
DLNFD & 9.53 & 2 & 0.009 \\
GRISK & 1.09 & 2 & 0.580 \\
All & $\mathbf{5 6 . 7 3}$ & $\mathbf{1 0}$ & $\mathbf{0 . 0 0 0}$ \\
\end{tabular}

\subsection{Impact to GDP Growth}

The results ofimpulse response shows that financial development have a positive impact in improving GDP growth and significant in quarter 2 (Figure 8). Meanwhile, an increase of inflation will reduce GDP growth significantly during quarter 2 to 5 . The increase of TOT will 
also significantly reduce the GDP during these cond to third quarter. In addition, the increase of excess money will also reduce GDP significantly in quarter 2. However, the impact of increased risk due to market imperfection/assymetric information to GDP tends to be not significant.
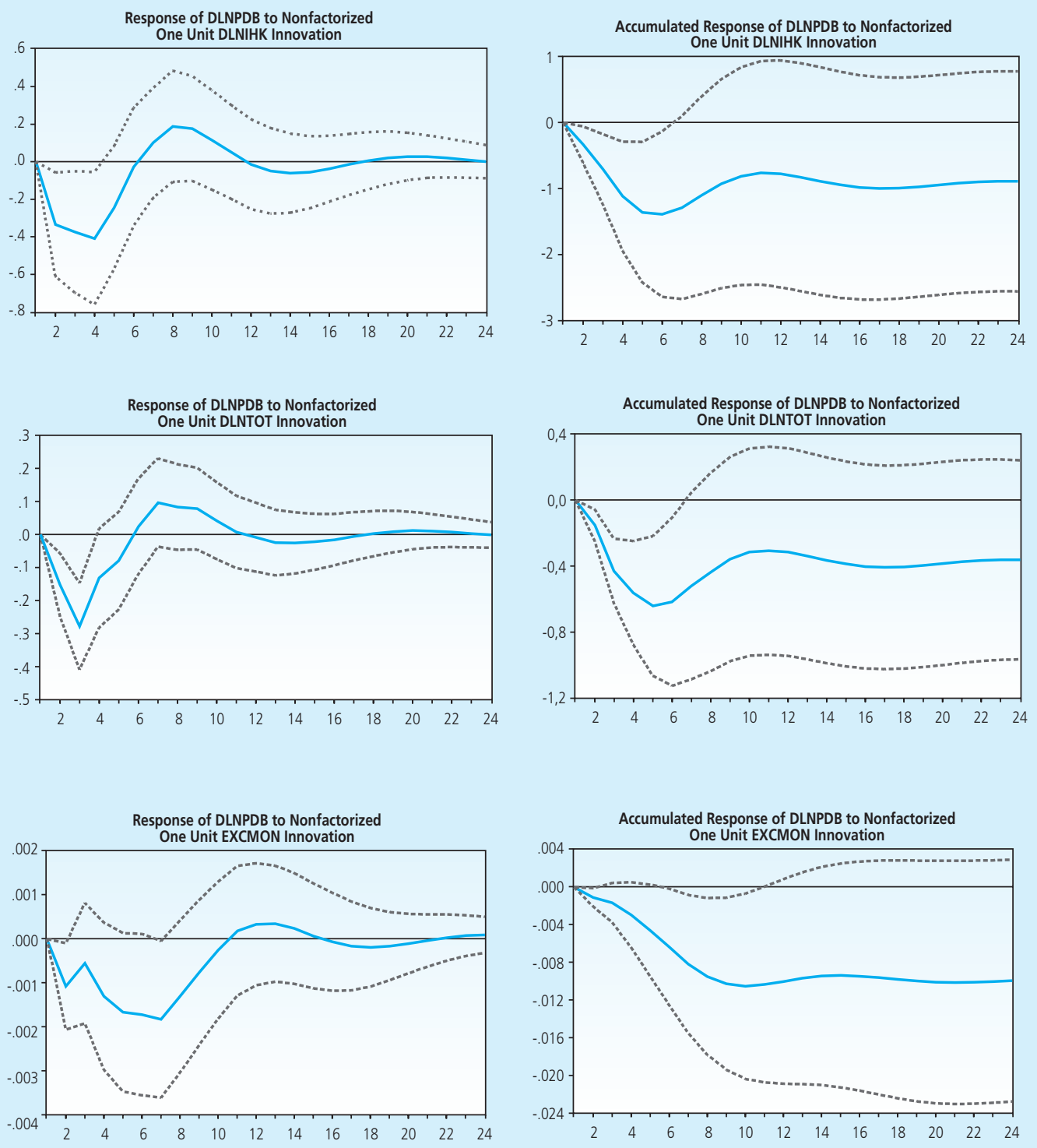

Figure 8. The Shock Impact of Inflation, TOT development, Excess Money Growth, Financial Development and Risk Changes against GDP Growth 

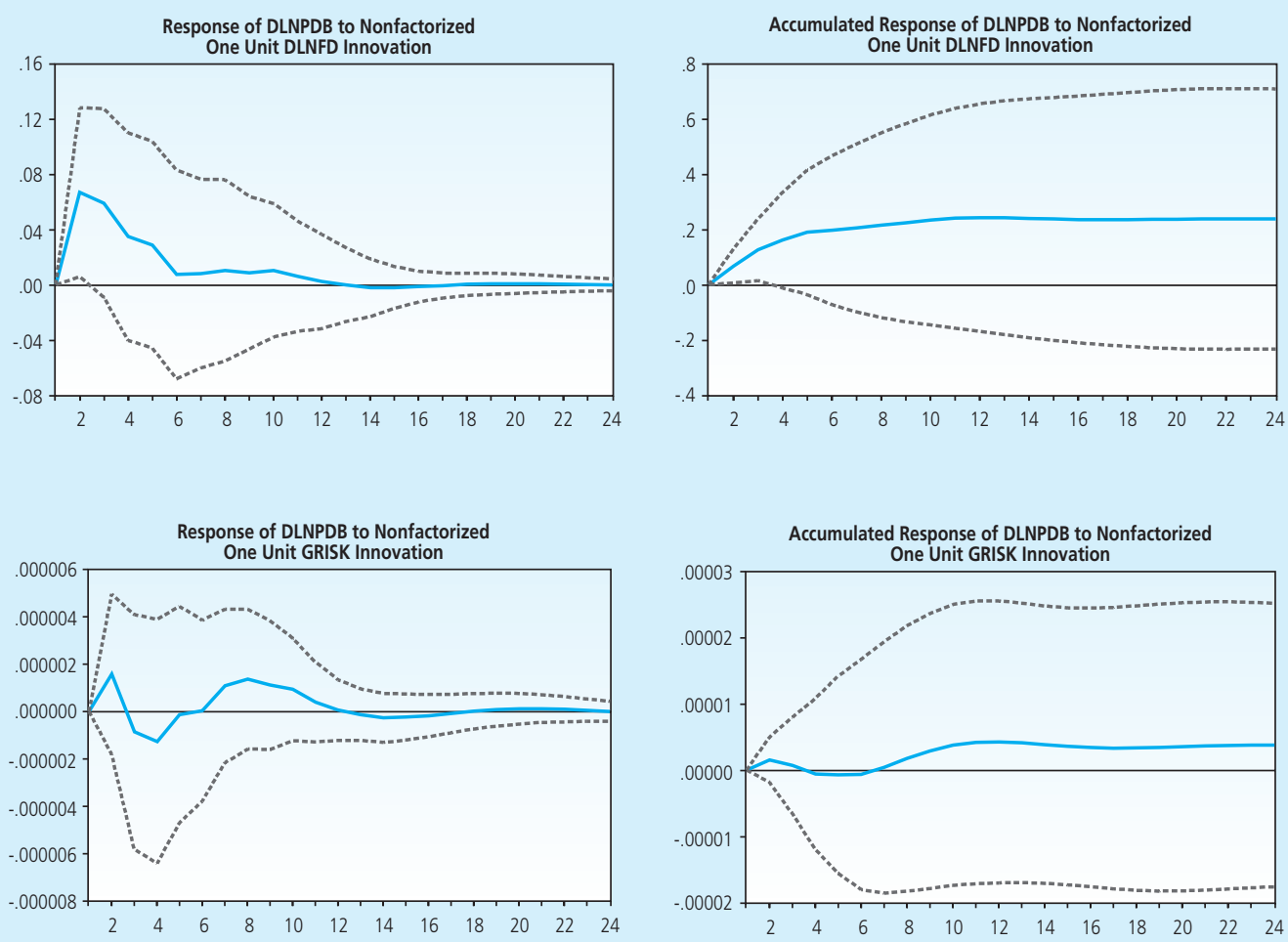

Figure 8. The Shock Impact of Inflation, TOT development, Excess Money Growth, Financial Development and Risk Changes against GDP Growth (continued)

In aggregate, the rise of inflation, TOT and the excess money growth will reduce GDP growth, while financial development will increase it. Cumulatively, an increase of financial development of $1 \%$ will give additional increase in GDP of $2.4 \%$ in 2.5 years (Figure 9). In contrast, a decrease of financial development of $1 \%$ will cause accumulation of GDP decline of $2.4 \%$ in 2.5 years.

Furthermore, using the variance decomposition analysis shows that excess money growth, TOT development and price movement are variables that contribute most in explaining the GDP movements in long-term, respectively by $27 \%, 11 \%$ and $9 \%$ (Table 3). While financial development contributes only about $2.6 \%$ as well the risk factor only contribute less than $1 \%$. 


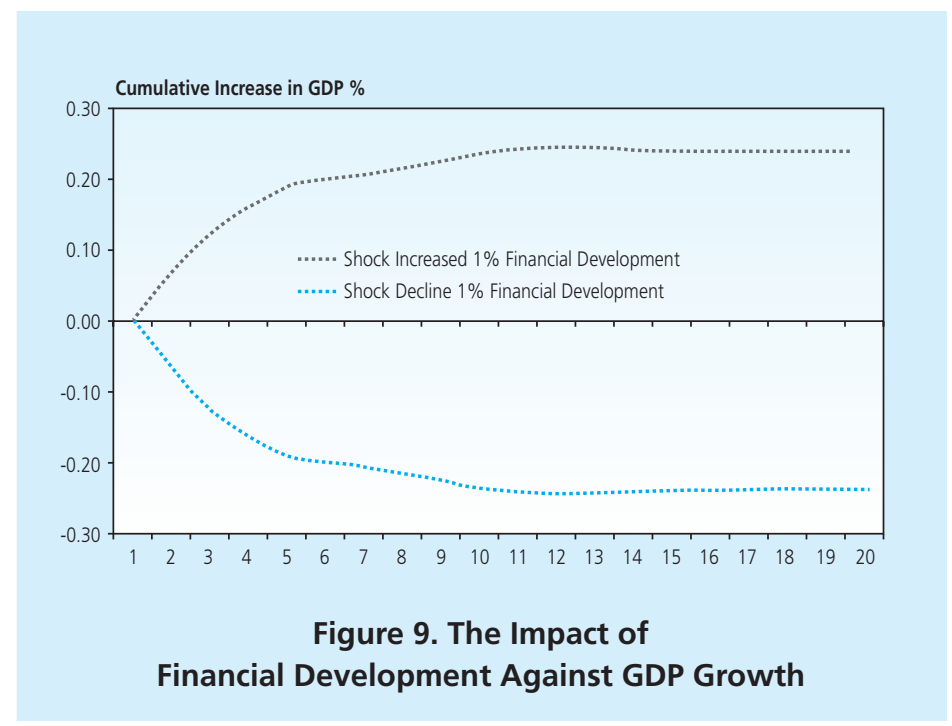

\begin{tabular}{c|c|c|r|r|r|r|r|}
\multicolumn{7}{|c|}{ Table 3. } \\
\multicolumn{2}{|c|}{ Variance Decomposition of DLNPDB } \\
Period & S.E. & DLNPDB & DLNIHK & DLNTOT & EXCMON & DLNFD & GRISK \\
\hline 1 & 0,026 & 100,000 & 0,00 & 0,000 & 0,000 & 0,000 & 0,000 \\
2 & 0,033 & 81,750 & 5,535 & 11,579 & 0,623 & 0,438 & 0,075 \\
3 & 0,040 & 70,384 & 8,575 & 13,504 & 6,495 & 0,374 & 0,669 \\
4 & 0,044 & 62,215 & 9,940 & 12,844 & 13,955 & 0,423 & 0,622 \\
5 & 0,046 & 56,466 & 10,170 & 11,625 & 20,609 & 0,574 & 0,555 \\
6 & 0,048 & 52,796 & 9,954 & 10,869 & 24,969 & 0,876 & 0,536 \\
7 & 0,049 & 50,784 & 9,659 & 10,685 & 27,004 & 1,308 & 0,560 \\
8 & 0,049 & 49,859 & 9,440 & 10,822 & 27,481 & 1,800 & 0,598 \\
9 & 0,050 & 49,475 & 9,314 & 10,998 & 27,326 & 2,262 & 0,624 \\
10 & 0,050 & 49,281 & 9,249 & 11,078 & 27,129 & 2,629 & 0,633 \\
\hline
\end{tabular}

\subsection{Impact to Inflation}

Financial development and the increase of risk due to market imperfection/assymetric information do not influence inflation significantly. A significant factor in influencing inflation is the increase in TOT, which will raise inflation for 5 quarters, from quarter 2 to quarter 6 . In addition, the increase in excess money will also reduce GDP significantly for 11 quarters, from quarter 2 to quarter 12 . The results of impulse response showing that increase in TOT and excess money growth accumulatively will increase inflation. 

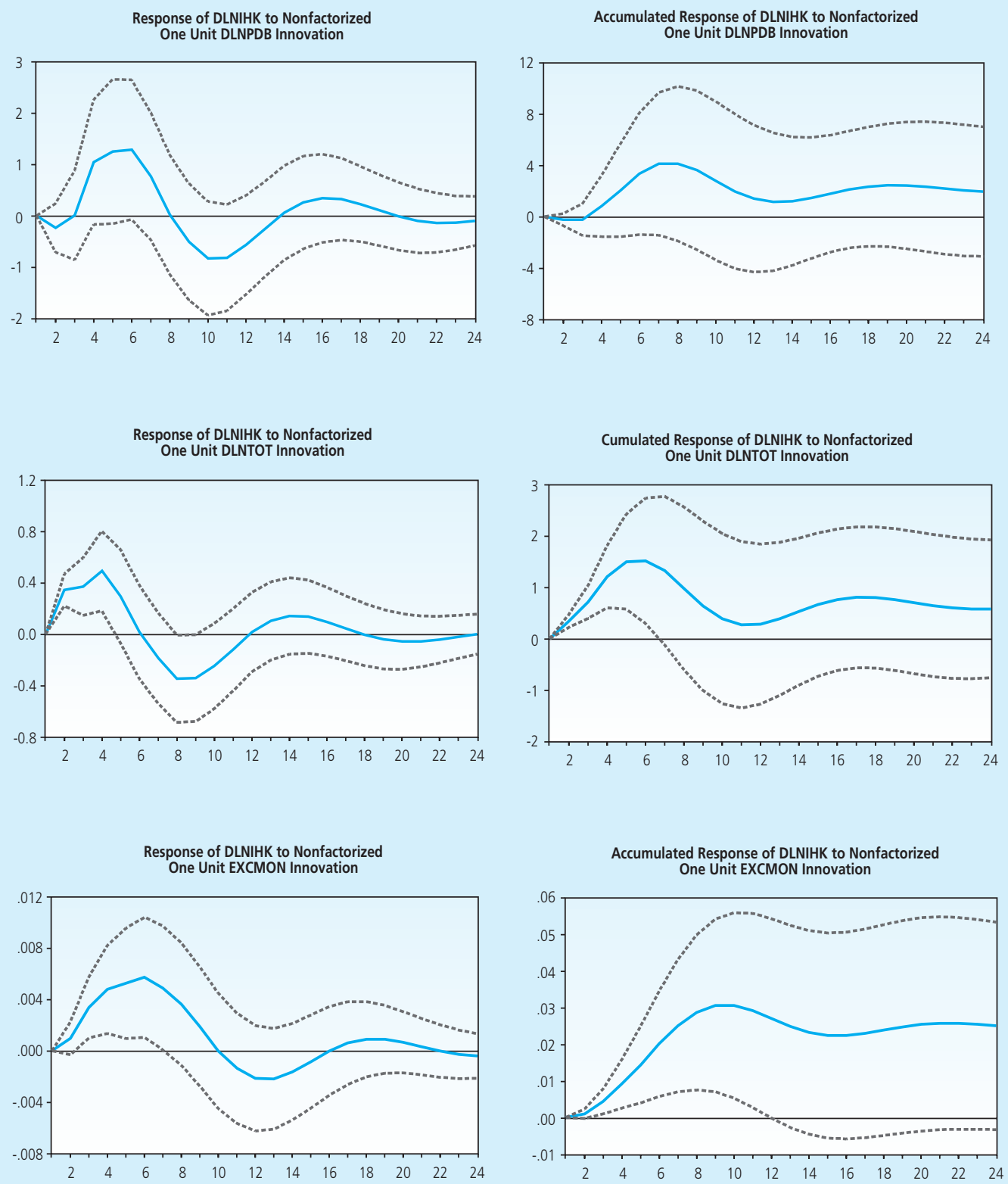

Figure 10.

The Impact of Changes in GDP Growth, TOT, Excess Money Growth, Financial Development and Changes in Risk on Inflation 

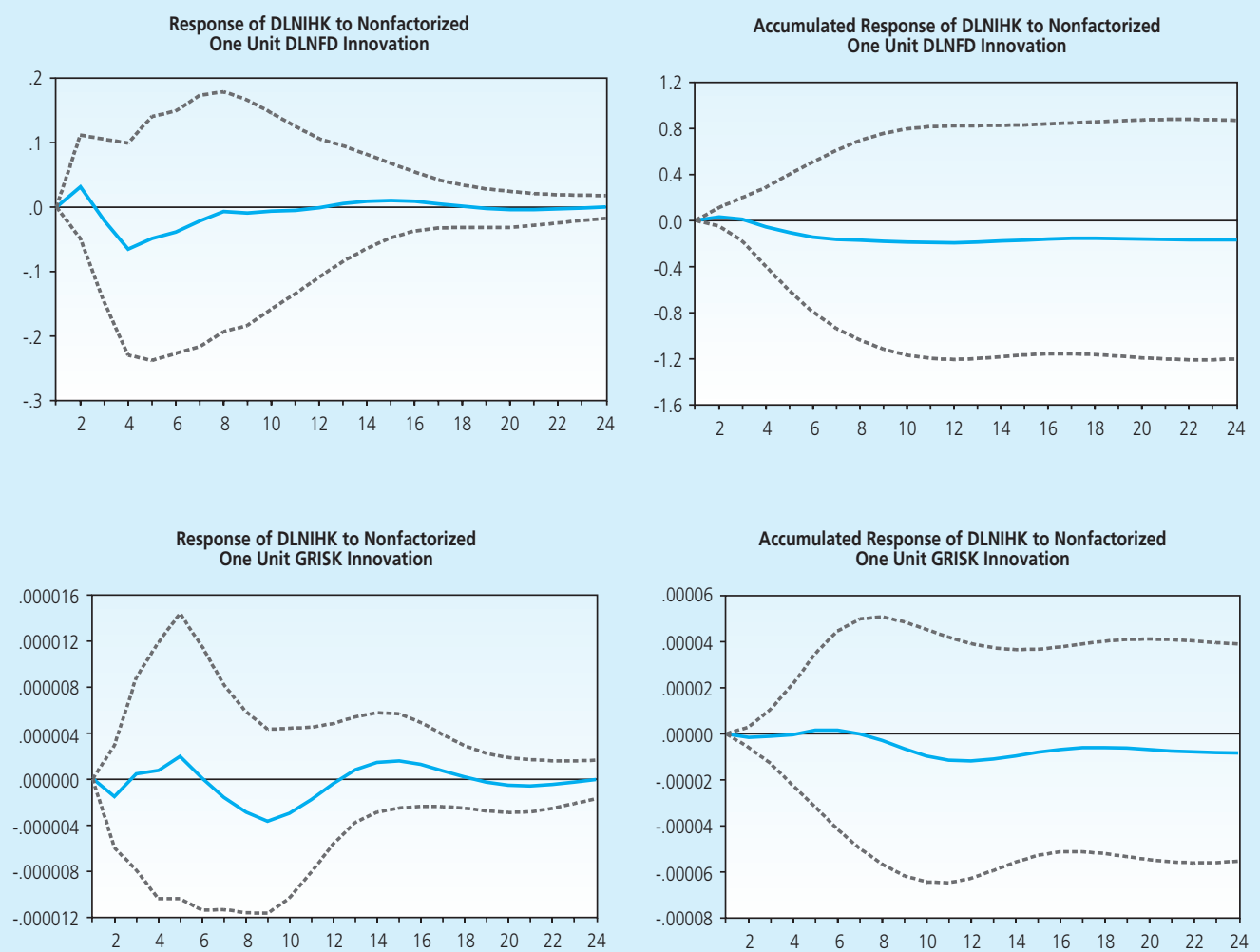

Figure 10.

The Impact of Changes in GDP Growth, TOT, Excess Money Growth, Financial Development and Changes in Risk on Inflation (continued)

\begin{tabular}{c|c|c|r|r|r|r|r|}
\multicolumn{7}{c}{ Table 4. } \\
\multicolumn{2}{|c|}{ Variance Decomposition of DLNIHK } \\
Period & S.E. & DLNPDB & DLNIHK & DLNTOT & EXCMON & DLNFD & GRISK \\
\hline 1 & 0,021 & 22,875 & 77,125 & 0,000 & 0,000 & 0,000 & 0,000 \\
2 & 0,032 & 42,434 & 38,577 & 17,416 & 1,221 & 0,058 & 0,293 \\
3 & 0,040 & 39,753 & 33,418 & 18,054 & 8,582 & 0,047 & 0,146 \\
4 & 0,045 & 29,168 & 32,137 & 22,651 & 15,769 & 0,164 & 0,111 \\
5 & 0,048 & 23,780 & 31,123 & 21,890 & 22,814 & 0,171 & 0,202 \\
6 & 0,049 & 21,424 & 28,777 & 19,244 & 30,189 & 0,189 & 0,177 \\
7 & 0,051 & 20,988 & 26,287 & 18,068 & 34,240 & 0,197 & 0,221 \\
8 & 0,052 & 20,345 & 25,022 & 18,978 & 35,073 & 0,197 & 0,385 \\
9 & 0,053 & 19,593 & 25,173 & 20,268 & 34,112 & 0,209 & 0,646 \\
10 & 0,053 & 19,030 & 25,862 & 20,954 & 33,133 & 0,216 & 0,804 \\
\hline
\end{tabular}


Based on the variance decomposition analysis for inflation, the increase of excess money, TOT and GDP movement are variables that contribute most in explaining the movement of inflation in the long run respectively by 33\%, 21\%and 19\% (Table 4). While financial development and risk factor only contribute less than $1 \%$.

\subsection{The Impact of Interaction between Financial Development with the Shock in Real Sector (TOT) and Monetary (Excess Money)}

The result of impulse response that incorporates interaction between the shock in the real sector and monetary with financial development shows that financial development has a positive role in dampening the negative impact of the shock on GDP growth (Fig.11 and 12). In contrast, financial development will help increasing (amplify) the positive impact of the shock on economic growth.

Cumulatively, increase of TOT by $1 \%$ would reduce GDP by $0.4 \%$ within 4 years, but if at the same time there was also an increase of financial development by $1 \%$, the cumulative impact of the decline in GDP in the period of 4 years will tend to be smaller, only amounting to $0.17 \%$. In contrast, if there is a TOT decreased of $1 \%$, then cumulatively will provide an additiona lincrease in GDP in the period of 4 years of $0.4 \%$. Interestingly, if the TOT decline by $1 \%$ is accompanied by increased financial development by $1 \%$, the cumulative impact of increase in GDP during the period of 4 years will be higher, amounting to $0.64 \%$.

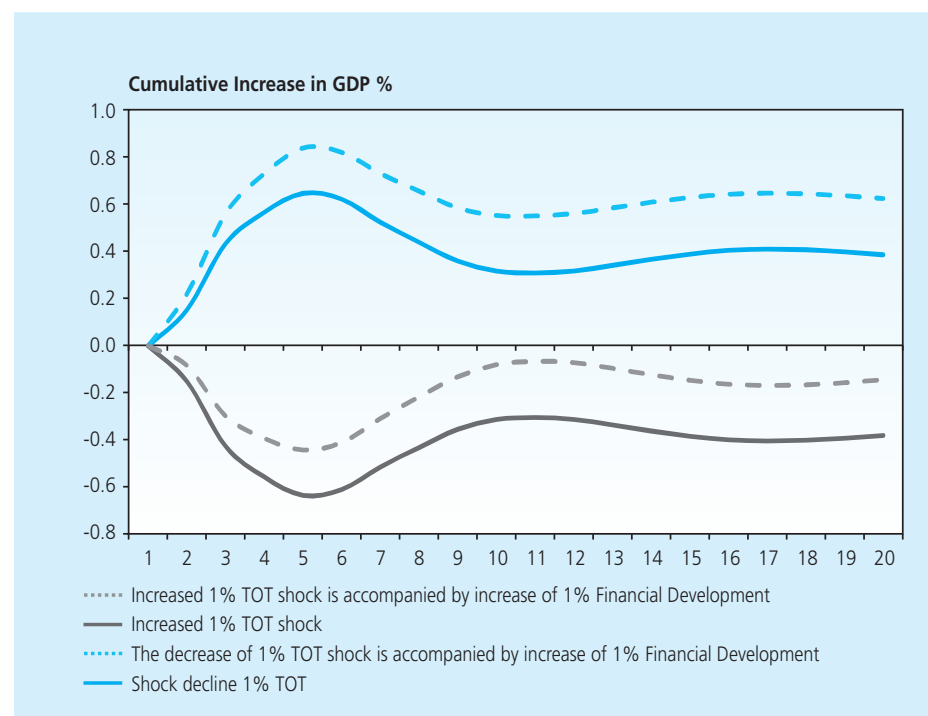

Figure 11. Impacts of Shock Interaction between TOT Development and Financial Development on GDP Growth 
Cumulatively, the growth of $1 \%$ excess money would reduce GDP by $1 \%$ within 2 years, but if at the same time there was an increase financial development of $1 \%$, the cumulative impact of the decline in GDPin the period of 2 years will be smaller, only amounting to $0.75 \%$. In contrast, if there is a decrease of $1 \%$ excess money, then cumulatively would raise GDP in the period of 2 year sat $1 \%$. However, if the decrease of $1 \%$ excess money is accompanied by increased financial development by $1 \%$ then the cumulative impact of increase in GDP during the period of two years will be higher, amounting to $1.25 \%$.

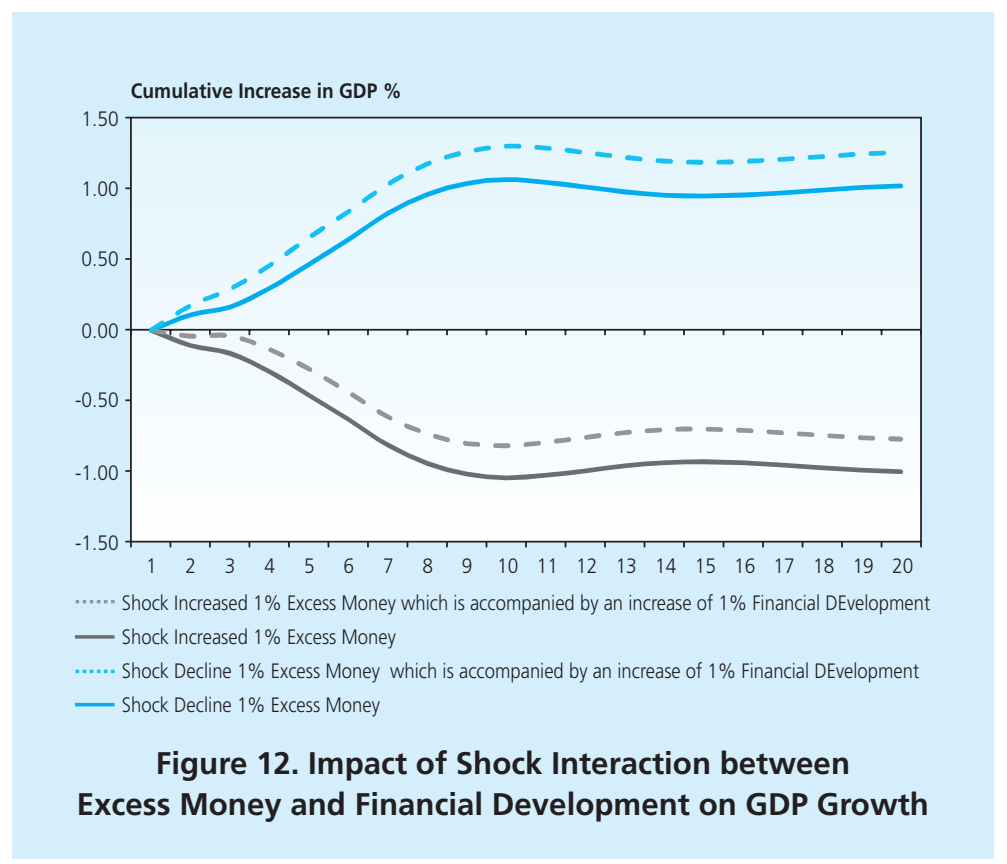

\section{CONCLUSION}

Financial development and economic growth hasa positive relationship, where the increasing financial development will have a positive impact on economic growth. However, the impact of risk increase due to market imperfection/assymetric information is not significant to GDP.

The interaction between the shock in real and monetary sector with financial development shows that financial development has a positive role dampening the negative shock impact on GDP growth, while the positive shock impact on economic growth will be amplified. 
Some factors that influence the movement of long-term growth is the increase of excess money, TOT and the price movement. Meanwhile, although the financial development has a positive role in the development of economic growth but its contribution is smaller compared to these factors.

Related to the price movement, financial development and increased risk due to market imperfection/assymetric information are not significant in influencing the inflation. This is in line with the finding that financial development and risk factors do not contribute greatly in explaining inflation dynamics in the long run. 


\section{REFERENCES}

Bacchetta, Philippe \& Ramon Caminal (2000), "Do capital market imperfections exacerbate output fluctuations?". European Economic Review, No. 44, pp. 449-468.

Beck, Thorsten, Mattias Lundberg \& Giovanni Majnoni (2006), "Financial Intermediary Development and Growth Volatility : Do Intermediaries Dampen or Magnify Shocks?" . Journal of International Money and Finance, Volume 25, Issue 7, pp. 1146-1167.

Enders, Walter (2004), Applied Econometric Time Series, Wiley Series in Probability and Statistics. John Wiley \& Sons, Inc.

Greene, William H. (2008), Econometric Analysis. Prentice Hall.

Guryay, Erdal, okan Veli Safakli \& Behiye Tuzel. (2007). "Financial Development and Economic Growth: Evidence from Nothern Cyprus". International Research Journal of Finance and Economics, Issue 8.

Kuneida, Takuma (2008). "Financial Development and Volatility of Growth Rates : New Evidence". MPRA Paper No. 11341.

Schumpeter, J.A. (1911), The Theory of Economic Development, Cambridge, Mass. Harvard University Press.

Stock, J.H. and M.W. Watson (2001), "Vector Autoregression".Journal of Economic Perspectives, 15,4 . 